\title{
PERFORMANSI GREENSHIP BUILDING PADA RUMAH TURI DI SURAKARTA \\ (PENEKANAN PADA WATER CONCERVATION DAN MATERIAL RESOURCE AND CYCLE)
}

\author{
Surya Arafat, Nur Rahmawati Syamsiyah \\ Program Studi Arsitektur Fakultas Teknik Universitas Muhammadiyah Surakarta \\ Jl. Ahmad Yani Tromol Pos 1 Pabelan Kartasura Surakarta \\ email : surya_arafat19@yahoo.com
}

\begin{abstract}
ABSTRAK
Green Architecture atau arsitektur hijau akhir-akhir ini sangat diminati oleh para arsitek dan konsumen. Konsep arsitektur hijau merupakan konsep perancangan bangunan yang ramah lingkungan dan berkelanjutan. Faktor-faktor dalam dan luar bangunan sangat diperhatikan agar minim dampak kerusakan sumber daya alam yang telah ada. Rumah Turi di Surakarta adalah sebuah hotel yang menjadi objek penelitian, untuk mencari kesesuaian antara bangunan dengan konsep green building. Metode dalam penelitian adalah kualitatif dengan mengacu pada Guidelines Green Building Council Indonesia. Lebih khusus lagi adalah pada Greenship for Existing Building. Beberapa lembaga sertifikasi bangunan hijau di dunia yang sudah berperan aktif, di antaranya BREEAM (Building Research Establishment's Environmental Assesment Method) di Inggris, LEED (Leadership in Energy and Environmental Design) di USA, Green Star (Standar Bangunan Hijau) di Australia. Indonesia melalui Green Building Council Indonesia memiliki parameter penilaian green building yang telah disesuaikan dengan iklim dan keadaan alam di Indonesia. Penelitian yang dilakukan menunjukkan bahwa konsep green building Hotel Rumah Turi dari segi pengelolaan air dan bahan material yang digunakan masih kurang maksimal. Nilai yang didapat adalah sebesar $50 \%$ dari 2 parameter yang digunakan. Hasil penilaian ini akan menjadi rekomendasi, sehingga diharapkan dapat memperbaiki pengelolaan air dan bahan material pada Hotel Rumah Turi Surakarta.
\end{abstract}

\section{Kata Kunci : green building, standarisasi green building, pengelolaan air}

\section{PENDAHULUAN}

Latar Belakang

Di era modern seperti sekarang ini konsep arsitektur hijau atau Green Architecture sangat digemari baik oleh arsitek maupun konsumen/klien. Dalam rancangan Green Architecture tidak hanya mengandalkan bentuk dan material yang alami yang dapat di daur ulang, tapi juga memperhatikan tingkat efektifitas dan keawetan, serta ramah lingkungan di sekitarnya.

Dengan kondisi tersebut di atas maka sebuah penelitian harus dilakukan untuk mengidentifikasi kategori green architecture pada bangunan yang telah beroperasi, yang memiliki konsep green building saat proses perencanaannya. Oleh karena itu penulis berniat meneliti tentang tolok ukur pada sebuah bangunan hijau dengan standar yang diambil dari Guidelines Greenship for Existing Building $\mathrm{GBCl}$ (Green Building Council Indonesia). Dalam pedoman Greenship sebagai perangkat penilaian terdiri atas acuan sebagai parameter penilaian, apakah bangunan masuk dalam kategori green building ataukah tidak.

Tempat yang digunakan sebagai objek penelitian adalah bangunan Hotel Rumah Turi di Surakarta. Bangunan ini merupakan salah satu bangunan dengan desain ecoarchitecture. Salah satu parameter dari Green Building Council Indonesia yang dipakai dalam penentuan kriteria bangunan hijau pada penelitian ini adalah Water Concervation dan Material Resource And Cycle. Parameter 
tersebut dipilih karena melihat fasad bangunan yang lebih menekankan pada penggunaan material bekas dan melihat bahwa penggunaan air yang lebih hemat dan lebih ramah lingkungan. Dengan penelitian tersebut diharapkan akan mengetahui sejauh mana penerapan konsep Green Building pada bangunan Rumah Turi Surakarta.

\section{Permasalahan}

Permasalahan yang dapat dirumuskan dalam penelitian yang dilakukan adalah:

"Sejauh mana bangunan Rumah Turi telah memenuhi standar persyaratan green building berdasarkan Greenship for Existing Building dari Green Building Council Indonesia yang menekankan pada parameter Water Concervation dan Material Resource and Cycle?"

\section{Tujuan}

Tujuan yang hendak dicapai dengan dilaksanakannya penelitian ini adalah untuk mengidentifikasi kesesuaian persyaratan green building menurut Green Building Council Indonesia dengan objek bangunan Rumah Turi di Surakarta.

\section{Manfaat}

Manfaat pelaksanaan penelitian ini secara khusus adalah untuk mengetahui kesesuaian penerapan konsep green building pada bangunan Rumah Turi sesuai dengan standar parameter dari Greenship Green Building Council Indonesia. Sedangkan secara lebih luas, hasil penelitian ini diharapkan dapat dijadikan percontohan dalam mendesain bangunan yang berkonsep green building dengan standar nasional yang telah disesuaikan dengan iklim tropis di Indonesia.

\section{TINJAUAN PUSTAKA \\ Green Architecture}

Konsep bangunan hijau adalah bangunan dimana di dalam perencanaan, pembangunan, pengoperasian serta dalam pemeliharaannya memperhatikan beberapa aspek dalam melindungi, menghemat, mengurangi penggunaan sumber daya alam, menjaga mutu baik bangunan maupun mutu udara di dalam ruangan, dan memperhatikan kesehatan penghuninya yang semuanya berdasarkan kaidah pembangunan berkelanjutan.
Suatu bangunan dapat disebut sudah menerapkan konsep bangunan hijau apabila berhasil melalui suatu proses evaluasi untuk mendapatkan sertifikasi bangunan hijau. Di dalam evaluasi tersebut tolok ukur penilaian yang dipakai adalah sistem rating (rating system).

Sistem rating (rating system) adalah suatu alat yang berisi butir-butir dari aspek yang dinilai yang disebut rating dan setiap butir rating mempunyai nilai (poin). Sistem rating (rating system) dipersiapkan dan disusun oleh Green Building Council yang ada di negara-negara tertentu yang sudah mengikuti gerakan bangunan hijau. Setiap negara tersebut mempunyai sistem rating masing-masing. Green Building Council Indonesia $(\mathrm{GBCl})$ saat ini telah memiliki rating sistem bernama greenship. Greenship menggunakan kriteria penilaian sedapat mungkin berdasar-kan standar lokal baku seperti Undang-Undang (UU), Keputusan Presiden (Keppres), Instruksi Presiden (Inpres), Peraturan Menteri (Permen), Keputusan Menteri (Kepmen), dan Standar Nasional Indonesia (SNI).

Menurut Brenda dan Robert Vale (1996) dalam bukunya "Green Architecture : Design for ASustainable Future" ada 6 prinsip dasar perencanaan Green Architecture, yaitu :

1. Conserving Energy, pengoperasian bangunan harus meminimalkan penggunaan bahan bakar atau energi listrik dengan memaksimalkan energi alam sekitar lokasi bangunan.

2. Working With Climate, mendesain bangunan harus berdasarkan iklim yang berlaku di lokasi tapak bangunan itu berada.

3. Minimizing New Resources, mendesain dengan meminimalisir kebutuhan sumber daya alam, agar sumber daya tersebut tidak habis dan dapat digunakan di masa mendatang.

4. Respect for Site, bangunan yang dibangun jangan sampai merusak kondisi tapak aslinya, dengan perubahan tapak seminimal mungkin.

5. Respect for User, memperhatikan semua pengguna bangunan dan memenuhi semua kebutuhannya. 


\section{Penilaian Green Architecture di Indonesia}

Keutamaan aspek hijau pada bangunan gedung di Indonesia ditujukan untuk memenuhi persyaratan kesehatan dan kenyamanan bangunan gedung. Beberapa peraturan menteri dapat menjadi acuan perwujudan bangunan hijau, seperti peraturan Menteri Pekerjaan Umum terkait RTH, aksesibilitas bangunan dan tata bangunan, peraturan Menteri Kesehatan terkait kesehatan dalam bangunan dan kualitas air. Standar Nasional Indonesia (SNI) dapat menjadi referensi/rujukan pembentukan bangunan hijau seperti SNI penyediaan air bersih, plumbing, ventilasi/penghawaan, pencahayaan dan bunyi.

Greenship bersifat khas Indonesia seperti halnya perangkat penilaian di setiap negara yang selalu mengakomodasi kepentingan lokal setempat. Program sertifikasi Greenship diselenggarakan oleh Komisi Rating $\mathrm{GBCl}$ secara kredibel, akuntabel dan penuh integritas. Greenship sebagai sebuah sistem rating terbagi atas enam aspek yang terdiri dari :

1. Tepat Guna Lahan (Appropriate Site Development/ASD)

2. Efisiensi Energi \& Refrigeran (Energy Efficiency \& Refrigerant/EER)

3. Konservasi Air (Water Conservation/WAC)

4. Sumber \& Siklus Material (Material Resources \& Cycle/MRC)

5. Kualitas Udara \& Kenyamanan Udara (Indoor Air Health \& Comfort/IHC)

6. Manajemen Lingkungan Bangunan (Building \& Enviroment Management)

Masing-masing aspek terdiri atas beberapa rating yang mengandung kredit yang masing-masing memiliki muatan nilai tertentu dan akan diolah untuk menentukan penilaian.

\section{METODE PENELITIAN Metode Umum}

Metode penelitian yang digunakan secara umum adalah metode kualitatif, yaitu menggunakan literatur pedoman green building, yang diamati aplikasinya pada objek penelitian. Tindak lanjut hasil penelitian adalah untuk melihat hubungan sebab akibat antara hasil pengukuran dengan kondisi eksisting.

\section{Fokus Penelitian}

Oleh karena banyaknya kriteria yang ditetapkan dalam penilaian dan pemilihan pada bangunan hijau menurut Green Building Council Indonesia, maka dalam penelitian akan mengambil dan menitikberatkan pada parameter Greenship for Existing Building tentang water concervation dan material reduce and cycle.

\section{Alat Ukur Penelitian}

Alat ukur penelitian menggunakan Pedoman/acuan dalam Greenship Guidelines For Existing Building dari Green Building Council Indonesia ( $\mathrm{GBCl}$ ).

\section{Pengumpulan Data}

a. Jenis Data

Jenis data atau variable yang digunakan untuk menilai ditentukan berdasarkan pada kondisi lapangan yang ada dan sesuai dengan persyaratan yang telah ada pada parameter Greenship for Existing Building.

b. Metode Pengumpulan Data

Pengumpulan data menggunakan metode survey/observasi lapangan. Data ditunjang oleh survey literatur untuk membantu kelancaran analisis dan referensi dalam penelitian.

c. Peralatan Penelitian

Beberapa peralatan yang digunakan oleh peneliti dalam mendukung proses ini adalah: kamera, alat tulis, lembar parameter dan alat perekam.

d. Analisis Data

Data hasil observasi dan wawancara selanjutnya akan dapat digunakan sebagai bahan dalam mengisi poin yang ada dalam tolok ukur yang telah ada dalam Greenship for Existing Building

\section{Objek Penelitian}

Objek penelitian adalah Rumah Turi Surakarta. Objek tersebut dipilih karena alasan sebagai berikut :

a. Keadaan fasad bangunan Rumah Turi yang mencerminkan sebuah bangunan dengan konsep eco-architecture yang terlihat dari banyaknya bukaan, vegetasi dan material bangunan yang berasal dari hasil recycling.

b. Lokasinya yang masih dalam lingkup wilayah Surakarta. 
c. Kemudahan dalam pencarian data, transportasi dan kenyamanan tempat sehingga memudahkan dalam pengumpulan data.

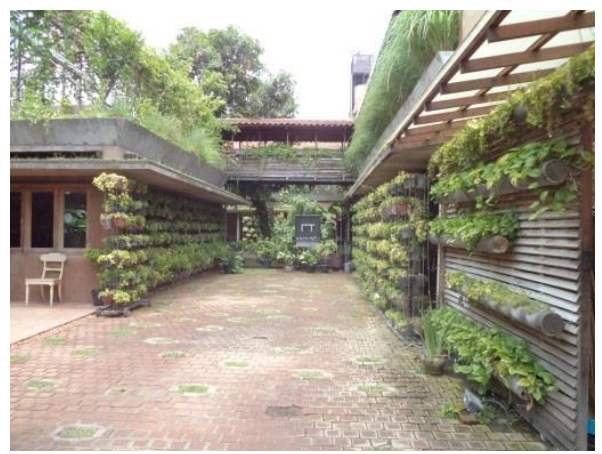

Gambar 1. Tampak Depan Rumah Turi yang Dipenuhi Vegetasi dalam Pot Gantung (Sumber: Dokumen Penulis, 2012)

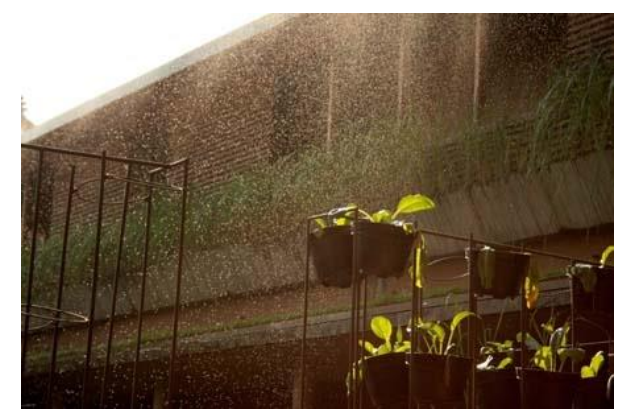

Gambar 2. Air dari Atap Sebagai Recycling dari Air Limbah untuk Menyirami Tanaman (Sumber: Dokumen Penulis, 2012)
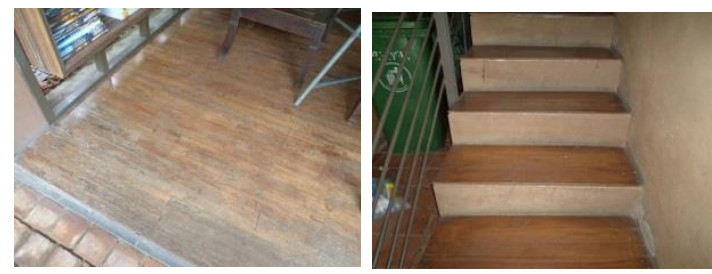

Gambar 3. Lantai Ruang dan Tangga Menggunakan Kayu Bekas yang Diolah Ulang (Sumber: Dokumen Penulis, 2012)
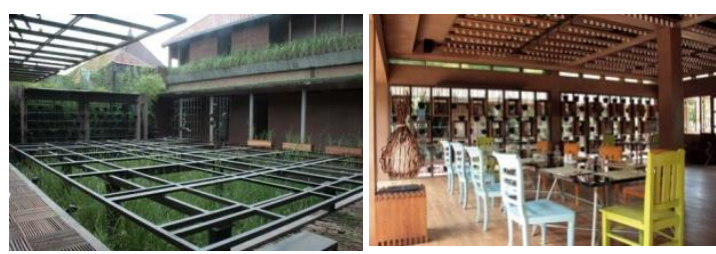

Gambar 4. Kolam untuk Pengolahan Limbah (Recycling, Reused) Sekaligus sebagai Panggung di Bagian Atasnya (Kiri), Restauran dengan Material Sebagian Besar dari Kayu Bekas (Kanan) (Sumber: Dokumen Penulis, 2012)

\section{ANALISIS DAN HASIL PENELITIAN Proses Observasi}

Proses observasi dimulai dengan pengenalan objek penelitian dengan bantuan pengelola Rumah Turi. Proses penelitian lebih banyak melakukan pengamatan lapangan dan ditunjang wawancara.

Objek pengamatan adalah beberapa hal yang langsung berhubungan dengan parameter yang digunakan dalam penilaian green building yaitu tentang Water Concervation dan Material Reduce and Cycle.

\section{Data dan Analisis Penelitian}

Berdasarkan hasil penelitian yang didapat dari wawancara dan observasi lapangan, diperoleh data primer yang digunakan sebagai bahan analisis penelitian. Analisis dan nilai hasil penelitian dapat dilihat dalam tabel berikut :

\section{Tabel 1.Analisis Penilaian Water Concervation}

\begin{tabular}{|c|c|c|c|c|}
\hline No & \multicolumn{2}{|c|}{$\begin{array}{c}\text { Parameter Green } \\
\text { Building }\end{array}$} & $\begin{array}{c}\text { Nilai/ } \\
\text { Nilai } \\
\text { standar }\end{array}$ & Keterangan \\
\hline 1 & \multirow{4}{*}{ 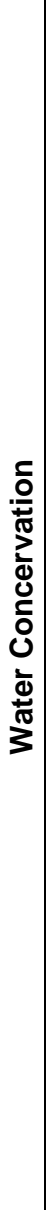 } & $\begin{array}{l}\frac{\text { Water }}{\text { Sub-Metering }} \\
\text { (Adanya } \\
\text { sub-meter } \\
\text { konsumsi air) }\end{array}$ & $\begin{array}{c}0 / 1 \\
\text { (tidak } \\
\text { memenuhi) }\end{array}$ & $\begin{array}{l}\text { Tidak ada sub } \\
\text { meter } \\
\text { konsumsi air di } \\
\text { tiap kamar } \\
\text { melainkan } \\
\text { terpusat jadi } \\
\text { satu, sulit } \\
\text { terkontrol. }\end{array}$ \\
\hline 2 & & $\begin{array}{l}\frac{\text { Water }}{\text { Monitoring }} \\
\text { Control } \\
\text { Adanya SOP } \\
\text { tentang } \\
\text { pemeliharaan } \\
\text { dan pemeriksaan } \\
\text { system plambing } \\
\text { secara berkala } \\
\text { dalam } 6 \text { bulan }\end{array}$ & $\begin{array}{c}0 / 2 \\
\text { (tidak } \\
\text { memenuhi) }\end{array}$ & $\begin{array}{l}\text { Tidak ada } \\
\text { standar } \\
\text { prosedur } \\
\text { operasi. } \\
\text { Hanya } \\
\text { pemeriksaan } \\
\text { secara mandiri } \\
\text { dengan } \\
\text { system out } \\
\text { sourcing. }\end{array}$ \\
\hline 3 & & $\begin{array}{l}\text { Fresh Water } \\
\text { Efficiency } \\
\text { SNI } \\
\text { 03-7065-2005 = } \\
\text { tentang Tata } \\
\text { Cara } \\
\text { Pelaksanaan } \\
\text { Sistem Plambing }\end{array}$ & $\begin{array}{c}5 / 8 \\
\text { (sedikit } \\
\text { memenuhi) }\end{array}$ & $\begin{array}{l}\text { Untuk } \\
\text { sementara } \\
\text { penggunaan } \\
\text { air belum bisa } \\
\text { di tekan } \\
\text { penghematan- } \\
\text { nya, konsumsi } \\
\pm 150 \text { liter/ } \\
\text { kamar/hari.(ho } \\
\text { tel melati) }\end{array}$ \\
\hline 4 & & $\begin{array}{l}\text { Water Quality } \\
\text { Menunjukkan } \\
\text { bukti } \\
\text { laboratorium } 6 \\
\text { bulan terakhir } \\
\text { dari air sumber } \\
\text { primer sesuai } \\
\text { dengan kriteria } \\
\text { air bersih }\end{array}$ & $\begin{array}{c}0 / 1 \\
\text { (tidak } \\
\text { memenuhi) }\end{array}$ & $\begin{array}{l}\text { Tidak ada } \\
\text { bukti } \\
\text { laboratorium }\end{array}$ \\
\hline
\end{tabular}




\begin{tabular}{|c|c|c|c|c|}
\hline No & \multicolumn{2}{|c|}{$\begin{array}{c}\text { Parameter Green } \\
\text { Building }\end{array}$} & $\begin{array}{c}\text { Nilai// } \\
\text { Nilai standr } \\
\end{array}$ & Keterangan \\
\hline 5 & \multirow{4}{*}{$\begin{array}{l}\text { ㅇ } \\
\frac{0}{\pi} \\
\frac{\pi}{d} \\
0 \\
\frac{0}{0} \\
0 \\
\frac{1}{\pi} \\
\frac{\pi}{3}\end{array}$} & $\begin{array}{l}\text { Recycled } \\
\text { Water } \\
\text { Menggunakan } \\
\text { air daur ulang } \\
\text { dengan } \\
\text { kapasitas yang } \\
\text { cukup untuk } \\
\text { kebutuhan } \\
\text { make up water } \\
\text { cooling tower, } \\
\text { flushing WC, } \\
\text { sesuai dengan } \\
\text { standar WHO, } \\
\text { air bersih } \\
\text { sesuai } \\
\text { Permenkes } \\
\text { No.416 Tahun } \\
\text { 1990 }\end{array}$ & $\begin{array}{c}3 / 5 \\
\text { (sedikit } \\
\text { memenuhi) }\end{array}$ & $\begin{array}{l}\text { Ada proses } \\
\text { daur ulang } \\
\text { hujan } \\
\text { buatan, } \\
\text { flushing WC } \\
\text { dan } \\
\text { menyiram } \\
\text { tanaman, } \\
\text { namun } \\
\text { kurang } \\
\text { memenuhi } \\
\text { untuk } \\
\text { kebutuhan } \\
\text { cooling } \\
\text { tower dan air } \\
\text { daur ulang } \\
\text { tidak untuk } \\
\text { konsumsi }\end{array}$ \\
\hline 6 & & $\begin{array}{l}\frac{P \text { Portable }}{\text { Water }} \\
\frac{\text { sistem filtrasi }}{\text { yang }} \\
\text { menghasilkan } \\
\text { air minum } \\
\text { sesuai } \\
\text { Permenkes } \\
\text { No. } 492 \text { Tahun } \\
\text { 2010 tentang } \\
\text { Persyaratan } \\
\text { Kualitas Air } \\
\text { Minum }\end{array}$ & $\begin{array}{c}0 / 1 \\
\text { (tidak } \\
\text { memenuhi) }\end{array}$ & $\begin{array}{l}\text { Tidak ada air } \\
\text { daur ulang } \\
\text { yang } \\
\text { digunakan } \\
\text { untuk air } \\
\text { minum }\end{array}$ \\
\hline 7 & & $\begin{array}{l}\frac{\text { Deep Well }}{\text { Reduction }} \\
\text { Konsumsi air } \\
\text { yang } \\
\text { menggunakan } \\
\text { deep well } \\
\text { maksimum } \\
20 \% \text { dari } \\
\text { konsumsi air } \\
\text { secara } \\
\text { keseluruhan }\end{array}$ & $\begin{array}{c}2 / 2 \\
\text { (memenuhi) }\end{array}$ & $\begin{array}{l}\text { Konsumsi air } \\
\text { bersih dari } \\
\text { deep well }\end{array}$ \\
\hline 8 & & $\begin{array}{l}\text { Water Tap } \\
\text { Efficiency } \\
50 \%-80 \% \text { dari } \\
\text { total unit keran } \\
\text { air pada area } \\
\text { publik } \\
\text { menggunakan } \\
\text { fitur auto stop. }\end{array}$ & $\begin{array}{l}\text { 0/2 (tidak } \\
\text { memenuhi) }\end{array}$ & $\begin{array}{l}\text { Tidak ada } \\
\text { kran system } \\
\text { otomatis }\end{array}$ \\
\hline & & umlah & $10 / 20$ & $\begin{array}{l}\text { Hanya } 50 \% \\
\text { standar } \\
\text { terpenuhi }\end{array}$ \\
\hline
\end{tabular}

(Sumber : Analisis Peneliti,2012)
Tabel 2. Tabel Penilaian Material Resource \& Cycle

\begin{tabular}{|c|c|c|c|c|}
\hline No & \multicolumn{2}{|c|}{$\begin{array}{c}\text { Parameter Green } \\
\text { Building }\end{array}$} & $\begin{array}{c}\text { Nilai/ } \\
\text { Nilai standr }\end{array}$ & Keterangan \\
\hline 1 & & $\begin{array}{l}\frac{\text { Non Ods }}{\text { Usage }} \\
\text { Menggunakan } \\
\text { seluruh sistem } \\
\text { pendingin } \\
\text { ruangan } \\
\text { dengan bahan } \\
\text { refrigerant yang } \\
\text { memiliki ODP = } \\
0 \text { (non CFC dan } \\
\text { non HCFC). }\end{array}$ & $\begin{array}{c}2 / 2 \\
\text { (memenuhi) }\end{array}$ & $\begin{array}{l}\text { Menggunakan } \\
\text { AC jenis } \\
\text { Neoplasma } \\
\text { With Purifying, } \\
\text { jetcool, } \\
\text { Deodorizing } \\
\text { filter, filter } \\
\text { NCB( Nano } \\
\text { Carbon Ball) }\end{array}$ \\
\hline 2 & 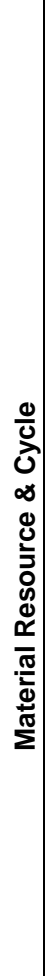 & $\begin{array}{l}\text { Material } \\
\text { Purchasing } \\
\text { Practice } \\
\text { Sesuai daftar } \\
\text { Material yang } \\
\text { Ramah } \\
\text { Lingkungan : } \\
80 \% \text { Produksi } \\
\text { regional, 30\% } \\
\text { Bersertifikat SNI } \\
\text { / ISO / ecolabel, } \\
5 \% \text { Material } \\
\text { didaur ulang, } \\
10 \% \text { Material } \\
\text { Bekas, 2\% } \\
\text { Material } \\
\text { Terbarukan, } \\
30 \% \text { Material } \\
\text { modular, 100\% } \\
\text { Kayu } \\
\text { bersertifikasi, } \\
2.5 \% \text { Lampu } \\
\text { yang tidak } \\
\text { mengandung } \\
\text { merkuri, non } \\
\text { asbestos, } \\
\text { rendah } \\
\text { formaldehyde, } \\
\text { emisi VOC } \\
\text { rendah }\end{array}$ & $\begin{array}{l}1 / 3 \text { (sedikit } \\
\text { memenuhi) }\end{array}$ & $\begin{array}{l}\text { Material kayu } \\
\text { berasal dari } \\
\text { material } \\
\text { bekas } \\
\text { bantalan rel } \\
\text { kereta api dan } \\
\text { bekas gempa } \\
\text { Jogja } 2006 .\end{array}$ \\
\hline 3 & & $\begin{array}{l}\frac{\text { Waste }}{\text { Management }} \\
\text { Practice } \\
\text { prinsip 3R } \\
\text { (Reduce, } \\
\text { Reuse, Recycle) } \\
\text { dalam } \\
\text { pengolahan } \\
\text { sampah }\end{array}$ & $\begin{array}{c}3 / 4 \\
\text { (memenuhi) }\end{array}$ & $\begin{array}{l}\text { SOP } \\
\text { pengolahan } \\
\text { sampah yang } \\
\text { terlaporkan } \\
\text { setiap } 6 \text { bulan } \\
\text { belum ada, } \\
\text { namun prinsip } \\
\text { 3R sudah } \\
\text { berjalan }\end{array}$ \\
\hline 4 & & $\begin{array}{l}\frac{\text { Hazardous }}{\text { Waste }} \\
\text { Management } \\
\text { SOP } \\
\text { pengolahan } \\
\text { limbah B3 }\end{array}$ & $\begin{array}{c}0 / 2 \\
\text { (tidak } \\
\text { memenuhi) }\end{array}$ & $\begin{array}{l}\text { Tidak ada } \\
\text { laporan } \\
\text { tertulis }\end{array}$ \\
\hline
\end{tabular}




\begin{tabular}{|c|c|c|c|}
\hline No & $\begin{array}{l}\text { arameter Green } \\
\text { Building }\end{array}$ & $\begin{array}{c}\text { Nilai/ } \\
\text { Nilai standr }\end{array}$ & Keterangan \\
\hline 5 & $\begin{array}{l}\text { Management } \\
\text { Of Used Good } \\
\text { SOP dan } \\
\text { laporan pe- } \\
\text { nyaluran barang } \\
\text { bekas yang } \\
\text { masih dapat } \\
\text { dimanfaatkan } \\
\text { kembali berupa } \\
\text { furniture, } \\
\text { elektronik, dan } \\
\text { suku cadang }\end{array}$ & $\begin{array}{c}0 / 1 \\
\text { (tidak } \\
\text { memenuhi) }\end{array}$ & $\begin{array}{l}\text { Tidak ada } \\
\text { laporan } \\
\text { tertulis dalam } \\
6 \text { bulan } \\
\text { terakhir }\end{array}$ \\
\hline \multicolumn{2}{|r|}{ Jumlah } & $6 / 12$ & $\begin{array}{c}\text { Hanya } 50 \% \\
\text { standar } \\
\text { terpenuhi }\end{array}$ \\
\hline
\end{tabular}

(Sumber : Analisis Peneliti,2012)

Dalam penelitian ini diperoleh hasil bahwa sebagian besar aspek green building telah diterapkan dalam bangunan Rumah Turi. Berikut adalah beberapa penjelasan tentang penerapan kedua parameter tersebut:

a. Pengolahan air atau filtrasi dilakukan menggunakan bahan dan sistem alami yaitu menggunakan vegetasi peresap air kotor, pasir, kerikil, dan batu. Kemudian hasilnya ditampung dan digunakan sebagai hujan buatan, flushing toilet, menyiram tanaman dan air mancur.

b. Menggunakan sumur dalam atau deep well sebagai pemasok air bersih. PDAM hanya digunakan bila air Deep Well minim.

c. Sebagian besar material menggunakan material bekas. antara lain: pagar depan yang terbuat dari rangkaian paku-paku bekas yang dilas satu per satu dan digabung menjadi pagar, kayu pada lantai atas menggunakan kayu bekas dan berlubang, meja dan kursi ruang santai dari material kayu bekas bantalan rel kereta api, kemudian cat dinding luar bangunan yang berwarna coklat berasal dari bata yang ditumbuk dan dicampur dengan semen hingga berwarna coklat dan lengket dengan dinding.

Selain penyelesaian masalah air dan penggunaan material interior yang umumnya memiliki prinsip recycling dan reused, Rumah Turi memberikan fenomena kenyamanan melalui aspek vegetasi yang penanamannya cukup menarik. Secara langsung memberikan view menarik dan efek termal lingkungan yang memberikan kesejukan/kesegaran.

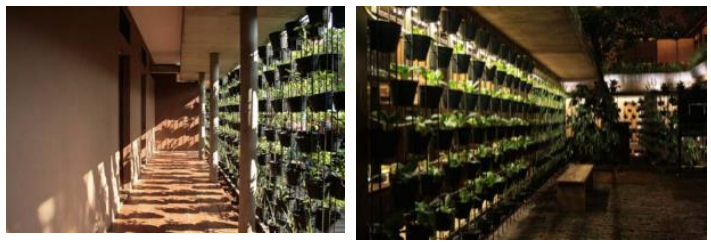

Gambar 5. Vegetasi Sayuran dalam Pot yang Dipasang di Selasar Depan Kamar Hotel,

Berfungsi Juga Sebagai Shading

(Sumber: Dokumen Penulis, 2012)
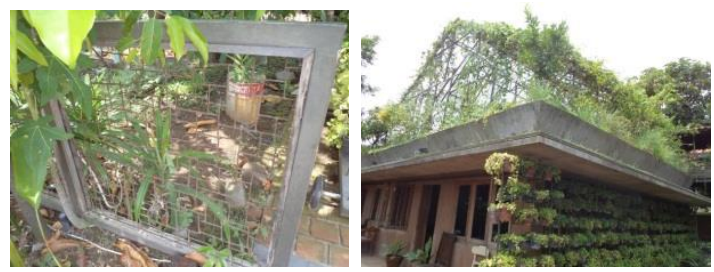

Gambar 6. Vegetasi Sebagai Atap (Kanan) dan Pagar yang Dibuat dari Paku-Paku Bekas yang Dilas

(Sumber: Dokumen Penulis, 2012)

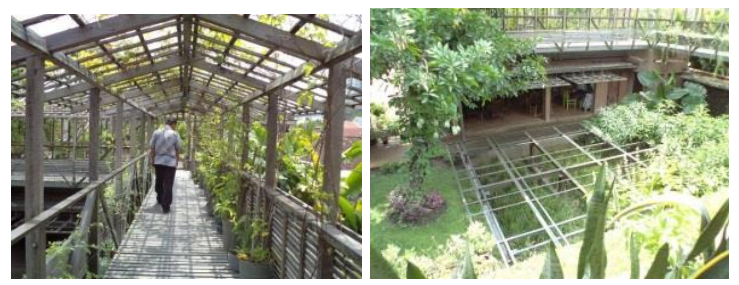

Gambar 7. Selasar di Lantai 2 Menuju Kamar Hotel (Kiri), Kolam Filtrasi Limbah yang Serbaguna (Kanan)

(Sumber: Dokumen Penulis, 2012)

\section{KESIMPULAN}

Dari hasil yang diperoleh maka dapat disimpulkan beberapa hal sebagai berikut :

1. Objek penelitian adalah pada bangunan Rumah Turi di Surakarta. Bangunan tersebut adalah berfungsi sebagai hotel dengan konsep eco desain/ eco architecture.

2. Penelitian yang dilakukan adalah mengenai sejauh mana Rumah Turi menerapkan parameter green building dari Green Building Council Indonesia berdasarkan Greenship for Existing Bilding yang menekankan pada 2 parameter yaitu : Water Concervation dan Material Reduce and Cycle.

3. Water Concervation terdiri dari Water Sub-Metering, Water Monitoring Control, Fresh Water Efficiency, Water Quality, Recycled Water, Potable Water, Deep Well Reduction dan Water Tap Efficiency 
4. Pada parameter Water Concervation, hanya Recycle Water, Fresh Water Efficiency dan Deep Well Reduction yang memenuhi standar parameter Greenship For Existing Building.

a. Pada Recycle Water mempunyai nilai 3 dari nilai standar 5 poin.

b. Pada Fresh Water Efficiency mempunyai nilai 5 dari standar 8 poin.

c. Pada Deep well Reduction mampunyai nilai 2 dari nilai standar 2 poin.

d. Total nilai pada parameter ini adalah 10 poin dari 20 nilai standar $(50 \%$ saja yang memenuhi standar).

5. Parameter Material Reduce And Cycle, meliputi Non ODS Usage, Material Purchasing Practice dan Waste Management Practice yang telah memenuhi kriteria sesuai parameter. Sementara 2 parameter lain tidak memenuhi standar, yaitu Hazardous Waste Management dan Management Of Used Good :

a. Pada Non Ods Usage mempunyai nilai 2 dari nilai maksimal 2 poin.

b. Pada Material Purchasing Practice mempunyai nilai 1 dari nilai maksimal 3 poin.

c. Pada Waste Management Practice mempunyai nilai 3 dari nilai maksimal 4 poin.

d. Pada Hazardous Waste Management mempunyai nilai 0 dari nilai maksimal 2 poin.

e. Pada Management of use good mempunyai nilai 0 dari nilai maksimal 1 poin.

f. Total nilai parameter ini adalah 6 poin dari 12 poin (50\% saja yang memenuhi standar).

6. Total poin dari kedua parameter tersebut adalah 16 poin dari total maksimal poin persyaratan adalah 32 poin. Dalam prosentase, $16 / 32 \times 100=50 \%$.

7. Berdasarkan total poin yang didapat dalam penelitian dan penilaian tersebut diatas, maka didapatkan bahwa desain ecoarchitecture Rumah Turi dalam hal ini penekanan pada aspek pelestarian air (Water Concervation) dan penggunaan material bekas (Material Reduce and Cycle) belum sepenuhnya memenuhi standar persyaratan atau masih separuh dari total nilai tertinggi dan penelitian tersebut hanya menekankan pada dua parameter dari 6 parameter yang ada.

\section{Rekomendasi}

\section{Bagi pengelola Rumah Turi}

1. Diharapkan memperbaiki sistem pengolahan air bekas agar dapat digunakan secara maksimal. Agar sesuai standar Green Building Council Indonesia, air bekas diolah menjadi air konsumsi dengan cara filtrasi dan mengolah dengan system yang lebih modern.

2. Diharapkan lebih meningkatkan eksplo-rasi penggunaan material yang ramah lingkungan agar keberlangsungan kehidupan lingkungan dapat terjaga.

3. Diharapkan selalu mendokumentasikan segala sesuatu mengenai pembelanjaan material agar mempermudah kontrol manajemen di masa mendatang.

4. Diharapkan membuat tempat pengolahan khusus sampah organik agar tidak mengganggu kenyamanan visual.

\section{Bagi Pembaca}

1. Diharapkan agar selalu berpartisipasi dalam mendisain bangunan dengan konsep green, karena semakin lama cadangan material dan sumber daya alam makin terbatas .

2. Diharapkan menggunakan dan memanfaatkan material yang sudah tidak terpakai agar dapat digunakan kembali menjadi bahan yang berguna.

3. Diharapkan adanya penelitian lanjutan pada Rumah Turi mengenai 4 parameter yang lainnya, yaitu : Tepat Guna Lahan (Appropriate Site Development / ASD), Efisiensi Energi \& Refrigeran (Energy Efficiency \& Refrigerant/EER), Kualitas Udara \& Kenyamanan Udara (Indoor Air Health \&Comfort/IHC) atau Manajemen Lingkungan Bangunan (Building \& Enviroment Management), yang belum dilaksananakan sebelumnya agar kriteria bangunan hijau dapat di ketahui dan diperbaiki bila dirasa kurang memenuhi kriteria

\section{Ucapan Terima Kasih}

Terima kasih penulis ucapkan kepada Bapak Paulus Mintarga atas ijinnya menjadikan Rumah Turi sebagai objek penelitian dan Bapak Krisharmanto yang telah membantu selama proses observasi. 


\section{DAFTAR PUSTAKA}

Brenda, Robert Vale (1996), Green Architecture: Design for a Sustainable Future,

Thames \& Hudson Ltd, New York

Karyono, Tri Harso, 2005, Arsitektur dan Kota Tropis Dunia Ketiga, Rajawali Pers., Jakarta

Nugroho Cahyo, A. 2009, Sertifikasi Arsitektur/Bangunan Hijau: Menuju Bangunan Yang Ramah Lingkungan, Jurnal Fakultas Teknik Sipil Universitas Lampung.

Peraturan Menteri PU 30/PRT/M/2006 Mengenai Pedoman Teknis Fasilitas Dan Aksesibilitas Pada Bangunan Gedung Dan Lingkungan.

Peraturan Menteri PU No. 5/PRT/M/2008 Mengenai Ruang Terbuka Hijau (RTH) B/277/Dep.III/LH/01/2009

UU No. 32 Tahun 2009 Tentang Perlindungan Dan Pengelolaan Lingkungan Hidup 